\title{
2h)
}

ESTUDIOS LITERARIOS

\section{LA HISTORIA DE LOS REYES MOROS DE GRANADA DE HERNANDO DE BAEZA. UNA CRÓNICA ENTRE EL ROMANCE DE FRONTERA, LA AUTOBIOGRAFÍA Y LA LEYENDA}

THE HISTORY OF THE MOORISH KINGS OF GRENADA BY HERNANDO OF BAEZA. A CHRONICLE THAT IS PART FRONTIER ROMANCE, PART AUTOBIOGRAPHY, AND PART LEGEND

\author{
María Mercedes Delgado PÉrez \\ Universidad de Sevilla \\ mmdelgado@us.es
}

Recibido: 06-03-2017

Aceptado: o8-01-2018

RESUMEN

En este trabajo trato de poner en claro algunos datos de la vida del cronista y trujamán Hernando de Baeza a través de los datos autobiográficos contenidos, de forma explícita o velada, en su crónica de los últimos años de la Granada nazarí, y añado algunos otros que se pueden deducir de sus propias palabras y de las de aquellos coetáneos o próximos a su tiempo que, interesados por su obra, nos han legado algunos escasos comentarios sobre sus vivencias.

Palabras clave: Hernando de Baeza, Historia de los reyes moros de Granada, Granada nazarí, Boabdil, Biografías.

\begin{abstract}
In this work I try to clarify some aspects from the chronicler and turjuman Hernando de Baeza's life, throughout autobiographical data, in a clear or hidden way, in his chronicle about the last years of the nazari Grenada, and I add some other ones we can deduce from his own words, and from other contemporary writers of his time that, very interested in his work, they have passed on some scarce information about his experiences.
\end{abstract}

Keywords: Hernando de Baeza, Historia de los reyes moros de Granada, Nazari Grenada, Boabdil, Biographies. 


\section{INTRODUCCIÓN}

Los elementos legendarios incluidos en la crónica redactada por Hernando de Baeza en las postrimerías del reino nazarí de Granada y primeros años de su constitución como reino cristiano hicieron que fuera clasificada como "curiosísimas páginas” por Pedro Antonio de Alarcón, que la empleó como material de primera mano para relatar un viaje por la Alpujarra. Aquí aparecen los dos elementos característicos de esta singular obra historiográfica, la más importante entre las castellanas para conocer los entresijos y vicisitudes de la Granada islámica en el siglo $\mathrm{XV}$ : por un lado, los evidentes rasgos literarios y, por otro, el testimonio fidedigno $\mathrm{y}$, en ocasiones, directo, de los hechos que narró. La valoración de la crónica presenta, por tanto, un doble juicio con dos elementos distintos e inseparables: los aspectos ficcionales y las aportaciones testimoniales. Esta visión es compartida por los géneros literarios con los que esta obra ha sido relacionada en diferentes estudios, especialmente el romance fronterizo ${ }^{2}$ y los inicios de la novela histórica ${ }^{3}$.

El mismo cronista queda desdibujado en su propia obra, base fundamental para la reconstrucción de su biografía, y aparece como un personaje enigmático del que se tienen pocos datos fehacientes, aparte de los escasos ofrecidos por él, efecto que quizá se explica por su condición, más que probable, de tornadizo y agente doble 4 , al que convino una apariencia huidiza y ambigua. Como personaje histórico, Baeza se presenta a sí mismo en un relato de confusa veracidad histórica, salpicado de notas literarias y, en esta operación, consigue transformarse en personaje legendario con rasgos tan misteriosos que, a día de hoy, resulta casi imposible separar los datos autobiográficos de los elementos mistificadores. No es lugar para señalar los muchos y, en ocasiones, contradictorios juicios emitidos sobre la persona y personalidad de Hernando de Baeza, una buena colección de interpretaciones realizadas con mayor o menor fundamento y fortuna: ha sido considerado intérprete castellano ante la corte nazarí, amigo íntimo de Boabdil5; secretario al servicio de los Reyes Católicos ${ }^{6}$, o su intérprete ${ }^{7}$; amigo y secretario del emir, lector y traductor de romances castellanos para él's; su cliente9; granadino y,

1 Alarcón, 1874: 26.

2 García Esteban, 2015: 22-23; Fosalba, 2002: 316-33o; Salicrú i Lluch, 1998b: 744; Mackay, 1988: 276; Arié, 1981: 157; Torres Fontes, 1972-1973: 247-248; Torres Balbás, 1948: 198-199; Menéndez Pidal, 1916: 235; Menéndez Pelayo, 1944: 166-167.

3 Fosalba, 2017: 130-133; Mata Induráin, 1995: 33; Deferrari, 1927: 63-64; Blanchard-Demougue, 1913: XLII-XLIV; Menéndez Pelayo, 1943: 139-140.

4 Opinión semejante en: Gilbert, 2014: 89-91.

5 Lafuente Alcántara, 1846: 116. Esta intimidad, y no sólo con Boabdil sino también con los moros principales, la supone, también, Joaquín Durán y Lerchundi (1893: 41).

${ }^{6}$ Simonet, 1897-1903: 792; Arié, 2001: 206.

7 Funes Pérez, 2016: 129.

8 Quesada Cañaveral y Piédrola, 1925: 63.

9 Menéndez Pelayo, 1943: 143. 
por tanto, morisco ${ }^{10}$; criado del secretario regio Hernando de Zafra ${ }^{11 ;}$ o de Martín de Alarcón $^{12}$; vecino de Granada tras la conquista ${ }^{13}$; eclesiástico castellano ${ }^{14}$; o escritor andaluz ${ }^{15}$. El juicio más prudente es el realizado por Diego Clemencín que lo sitúa, primero, como autor de la crónica y, luego, como "perito en la lengua arábiga y conocido del Rei Boabdil, quien por su médio envió á los Reyes Católicos algunos mensajes" . Es decir, se limita a los pocos detalles que se desprenden de la lectura de la propia crónica ${ }^{16}$.

Por mi parte, sin alejarme demasiado de este juicio prudente, voy a tratar de aportar algunos datos biográficos del autor de la Historia de los reyes moros de Granada que se desprenden de informaciones contenidas en sus páginas, incluida alguna añadida por los comentaristas y lectores que la manejaron durante el siglo $\mathrm{XVI}$, es decir, en fechas muy cercanas a su redacción definitiva ${ }^{17}$.

\section{DATOS AUTOBIOGRÁficos PARA UNA BIOGRAFÍA}

La mayor parte de los datos de que disponemos para trazar sobre base segura la biografía de Hernando de Baeza proceden de su propia crónica. Irrumpe en escena en la villa fronteriza de Alcaudete, hacia septiembre-octubre de $1483^{18}$, donde se encontraba viviendo "a la sazón"19, es decir, de forma circunstancial, o lo que es lo mismo, que no era natural de esta localidad. Allí, y de manera fortuita, conoció a Boabdil (Muhammad XI), que había sido proclamado emir a mediados del mes de julio de $1482^{20}$, y que estaba enfrentado a su padre, Muley Hacén (Abū l-Ḥasan 'Alī), y a su tío El Zagal (Muhammad b. Sacd al-Zagal), por hacerse con el control absoluto sobre el territorio nazarí. El joven emir fue liberado por los Reyes Católicos

10 Gozalbes Gravioto, 1999: 63; Coromines y Pascual, 2001: 513 .

"Vilar Sánchez, 2004: 95.

12 Tremlett, 2017: 253; Carriazo, 1989: 910-911.

13 Lafuente y Alcántara, 1868: IX-X; Cejador y Fracua, 1915: 454; Sánchez Alonso, 1947: 375.

14 Tinoco Díaz, 2017: 177, 179 y 489.

15 López de Coca Castañer, 2005: 34.

${ }_{16}$ Clemencín, 1821: 379 .

${ }_{17}$ Su realización se ha fechado en torno a 1505 (Carriazo, 1989: 394; López de Coca Castañer, 2005: 33; O'Callaghan, 2014: 9; Tinoco Díaz, 2015: 82 y 2017: 155; Szpiech, 2017: 26) y hasta 1510 (Carriazo, 1948: 431; Fosalba, 2017: 133), o bien en algún momento impreciso de los primeros años del siglo XVI (Lafuente y Alcántara, 1868: X; Cejador y Fracua, 1915: 454). La base de estas afirmaciones son algunos datos que la crónica contiene sobre la Granada posterior a la conquista, pero no es posible descartar que hubiera una redacción anterior a estos años (Gozalbes Gravioto, 1999: 63), que algunos pasajes sean testimonios recogidos prácticamente in situ, dada la viveza de muchos de los recuerdos vertidos por Baeza en su texto, o que estemos ante un recurso literario más, una forma de dar frescura y cadencia a la narración.

18 Atendiendo a las fuentes cristianas, especialmente Alonso de Palencia (1909: 92-93), así como a la fetua lanzada por los muftíes y alfaquíes granadinos contra Boabdil y a favor de los intereses de su padre (Vidal Castro, 200o: 196-197).

19 E-P, 243, Baeza: XI ro; RBME, Y/III/6, Baeza: 476 vº.

${ }_{20}$ Vidal Castro, 2000: 195 . 
en Córdoba tras su captura en la batalla de Lucena de 20 de abril de $1483^{21}$, que había terminado con un resultado verdaderamente desastroso para los intereses nazaríes, y se dirigió a las vanguardias fronterizas castellanas para recabar ayuda para su causa en contra de su padre y de su tío, con seguro de los monarcas cristianos.

Esta fecha ha sido objeto de controversia. Nicolás Velázquez Basanta ${ }^{22}$ la retrasa hasta finales de 1485 o principios de 1486, siguiendo a Gaspar Remiro ${ }^{23}$ quien, a su vez, se basaba en la crónica anónima musulmana Nub dat al-'așr ${ }^{24}$, en el Naf̣̂ alțīb de al-Maqqarī²5, en el propio Hernando de Baeza ${ }^{26}$, y en Lucio Marineo Sículo ${ }^{27}$. Sin embargo, por los datos que se desprenden de la documentación murciana y alicantina, esto no parece ser así, ya que Boabdil aparece entrando y saliendo de territorio cristiano libremente por la frontera de Murcia a lo largo del año 1485, y las noticias aportadas por los concejos de la zona indican que el emir se encontraba ocupado, por entonces, en alzar a su favor la parte oriental del territorio nazarí (Huéscar, al norte, o Almería, al sur) ${ }^{28}$. La documentación de archivo dice, además, que Boabdil contaba con seguro de los Reyes Católicos desde el 5 de julio de 1483, lo que le permitía, precisamente, circular con libertad a lo largo de la frontera y recabar para sí el apoyo de los caudillos cristianos fronterizos y de las autoridades de los territorios limítrofes, así como ofrecer seguros a los musulmanes que se acogiesen a su obediencia como vasallo de los reyes cristianos ${ }^{29}$.

Alcaudete era, entonces, un punto estratégico de primer orden en la frontera entre Castilla y Granada, pues era frecuente la partida de cabalgadas y las entradas de ejércitos cristianos desde esta villa hacia los territorios granadinos. Era lugar de reunión de estas acometidas y un baluarte en plena línea de defensa ocupado por hombres de armas, servidores, soldadesca, pendencieros, aventureros, espías, desertores, homicianos, forajidos, herejes, buscavidas, entretenedores de diversa índole, pero también de comerciantes, proveedores de los ejércitos, logreros y

${ }^{21}$ Idem, 196-197.

${ }^{22}$ Velázquez Basanta, 2002: 514.

${ }^{23}$ Gaspar Remiro, 1911: 25-30.

${ }_{24}$ Bustani, Quirós, 1940; Müller, 1863: 1-56 y 103-16o.

${ }^{25}$ Sigo la edición de Velázquez Basanta de al-Maqqarī y su cotejo con la Nubdatat al-așr (2002: 517).

${ }_{26}$ Desconozco la razón de Gaspar Remiro para usar como testimonio de su argumento a Hernando de Baeza, pues este deja claro que, al tiempo de la proclamación de su tío en junio de 1485, Boabdil se encontraba asentado en los Vélez de Almería (E-P, 243, Baeza: X ro y vo; RBME Y/III/6, Baeza: 476 ro ). Es más, la interpretación del propio copista del códice de El Escorial, no deja lugar a dudas sobre el momento de la liberación de Boabdil, pues indica, en nota al margen del fragmento donde se recoge el traslado del emir cautivo de Lucena a Porcuna y las capitulaciones subsiguientes, que "fue suelto el rey" (RBME, Y/III/6, Baeza: 474 r $^{\circ}$ ).

${ }_{27}$ Tampoco parece que Marineo Sículo avale la propuesta de Gaspar Remiro (Marineo Sículo, 1539: CLXXIII vo).

${ }_{28}^{28}$ Guirao López (1966): 100-102 y 105-106. Las aportaciones a esta polémica de Antonio de la Torre parecen definitivas, como apuntara Carriazo, para zanjar la cuestión y fijar la fecha en los últimos meses de 1483 (Torre, 1944; Carriazo, 1989: 514).

${ }_{29}$ AGS, PTR, LEG, 11, DOC.8. Es significativo que este seguro no tenga consignada fecha de caducidad, aunque las treguas se habían pactado por dos años (Ladero Quesada, 2002: 138-139). 
negociadores de todo género, incluyendo el rescate de cautivos, que se movían con amplia libertad en ese territorio nebuloso que constituía la frontera, una amplia zona caracterizada por la relajación de las normas morales y, también, de los dictados de los ordenamientos jurídicos, pues se atenuaba el rigor de la legislación contra delincuentes de todo orden en beneficio del poblamiento de un lugar expuesto a los envites del enemigo ${ }^{30}$.

No constan las circunstancias de la estancia de Baeza en Alcaudete, pero dado el afecto y familiaridad que muestra hacia el conde de Cabra, Diego Fernández de Córdoba ${ }^{31}$, que había sido, junto con su sobrino el alcaide de los donceles, llamado también Diego Fernández de Córdoba, protagonista principal en la batalla de Lucena, y dada la narración extensa que ofrece Baeza de estos hechos, no sería aventurado suponer que estuviera al servicio del señor de Baena. Además, a primeros de junio de 1483, el conde de Cabra había entrado con el rey Fernando por Alcaudete para hostigar en Montefrío a los musulmanes, junto con Alonso de Aguilar, durante las operaciones que el rey había llevado a cabo antes de capitular con el emir prisionero, tratando de aprovechar la circunstancia favorable de su captura $^{32}$. La expedición real había vuelto a Alcaudete, en dirección Córdoba, a finales de ese mes33.

Por ello podemos imaginar que Baeza se encontraba sirviendo en alguna de las huestes cristianas que combatían al emirato, seguramente en el círculo del conde de Cabra y, aunque desconocemos la circunstancia concreta del primer encuentro entre Baeza y el emir, sí sabemos, por las palabras del propio escritor, que tuvo lugar en un entorno bastante íntimo, pues se produjo por intercesión de un buen amigo suyo llamado Alhaje, mizuar de Boabdil34. A partir de entonces ambos personajes parecen profesarse estrecha simpatía y confianza mutua. Es posible suponer que en Alcaudete pudo ejercer como intérprete de Boabdil en sus tratos con caudillos cristianos con el fin de obtener favor para su causa esgrimiendo el seguro real, pues este había contado con diversos intérpretes a su servicio durante todo el cautiverio, tanto en su estancia en Porcuna como durante las negociaciones con los Reyes Católicos en Córdoba hasta su liberación 35 .

El propio Baeza dice que parte de las informaciones de los sucesos que relata las obtuvo directamente de boca de Boabdil, lo que indica que tuvo un trato bastante

30 Ruiz Povedano, 2009: 58-116.

${ }^{31}$ Es tan evidente que lo refleja en una anotación marginal el copista del códice de El Escorial: "mucho fauorece aquí el autor, y aún demasiadamente, el partido del conde" (RBME, Y/III/6, BAEZA: $\left.474 r^{\circ}\right)$.

$3^{2}$ Carriazo, 1989: 522.

33 Idem: 522-523.

34 E-P, 243, Baeza: XI ro ${ }^{\circ}$ RBME, Y/III/6, Baeza: 476 vo. Sobre el mizuar, mezuar o mexuar: Eguilaz y Yanguas, 1886: XVIII y 452; Steiger, 1932: 145. Baeza nos dice que el mizuar era la guarda mayor del emir y su justicia mayor, y que frecuentemente eran esclavos horros procedentes de Guinea (E-P, 243, Baeza: $2 \mathrm{v}^{\mathrm{o}}$ y VIII ro $\mathrm{r}^{\mathrm{o}}$ RBME, Y/III/6, Baeza: $467 \mathrm{v}^{\mathrm{o}}$ y $475^{\mathrm{r}}$ ).

35 Palencia, 19o9: 81 y 93 . 
familiar con él; tanto, que llegaron a hablar en castellano, lengua que el emir no usaba salvo en círculos muy íntimos, pues temía que la falta de soltura en el habla de un idioma no nativo le hiciese incurrir en algún error, y "el yerro en la boca de los reys pareçe muy feo" 36 .

Otra parte de las informaciones contenidas en su crónica hasta este momento las hubo de obtener en círculos muy próximos al conde de Cabra y, más en concreto, los hechos referentes a la batalla librada a orillas del Arroyo de Martín González. Aunque los reyes habían obrado con prudencia salomónica otorgando honores a los dos caudillos y parientes implicados en la victoria, los dos Diego Fernández de Córdoba, tío y sobrino ${ }^{37}$, la polémica entre los partidarios de uno y otro perduró en el tiempo y dio origen a dos versiones diferentes de la captura del joven emir, en la que cada facción, baenenses y lucentinos, se atribuía para sí la mayor parte de las glorias de esa batalla ${ }^{3}$. Hernando de Baeza, aunque reconoce en los hechos la participación del alcaide de los Donceles, muestra una especial predilección por el que llama "santo conde" 39.

Baeza seguía en Alcaudete en octubre de 1486, cuando Boabdil ya había vuelto a ser proclamado emir en Granada, encastillado en el Albaicín con sus partidarios frente a su tío, al-Zagal, que había sido proclamado emir tras el fallecimiento de su hermano Muley Hacén en junio de 1485, y era dueño del resto de la capital nazarí y de buena parte del emirato. Rigiendo todavía las capitulaciones asentadas con los Reyes Católicos en 1483, dice Baeza, Boabdil había vuelto a reclamar la ayuda para su causa de los fronteros cristianos y, por este motivo, se presentó en Alcaudete un mudéjar llamado Bobadilla, que llevaba recado de Abraham de Mora, intérprete y "alférez mayor" del emir4우, para buscar a Baeza y entregarle carta de su señor con el propósito de que le sirviera como mediador ante los Reyes Católicos ${ }^{41}$ Aquí se hace evidente la confianza que Boabdil tenía depositada en Baeza, confiándole una misión tan delicada en un momento muy determinante para sus intereses. Baeza declinó la invitación por ser peligroso el acceso al Albaicín, sitiado por los partidarios de al-Zagal ${ }^{42}$. La entrada del cronista en la ciudad debió de producirse hacia mayo de 1487, tras un nuevo llamamiento del emir a través de Bobadilla

${ }^{36}$ E-P, 243, Baeza: XI ro; RBME Y/III/6, Baeza: 476 vo . El copista del códice escurialense apunta en el margen: "respuesta notable deste rey".

37 Las resoluciones reales pueden verse en: AGS, RGS, LEG, 148311,2; AGS, RGS, LEG, 148311, 3 y AGS, RGS, LEG, 148311,4.

${ }^{38}$ Desacuerdo que perduró hasta el siglo XX (González de Amezúa y Mayo, 1915: 57-61).

39 E-P, 243, Baeza: 6 vo; RBME, Y/III/6, Baeza: $473 \mathrm{r}^{\circ}$.

40 Esta analogía identifica una institución cristiana con otra islámica que no cumple, propiamente, con la función descrita por el término castellano. Desde mediados del siglo XV, el alférez mayor se reducía al papel honorífico de portaestandarte real (Porras Arboledas, 2003: 78-79). Debe referirse, por tanto, a algún tipo de cargo militar, probablemente un jefe ( amīr $)$ al cargo de un gran estandarte ( $r a \bar{y} y a)$ (Viguera Molins, 2000: 440) porque Baeza, al comentar su amistad con Abraham de Mora, destaca sus cualidades militares (E-P, 243, Baeza: $5 \mathrm{r}^{\mathrm{r}}$; RBME Y/III/6, Baeza: $471 \mathrm{~V}^{\mathrm{o}}$ ).

${ }_{41}$ E-P, 243, Baeza: X vo-XI ro; RBME, Y/III/6, Baeza: 476 vº.

${ }^{42}$ Idem. 
después de su proclamación como emir en toda la capital, el día 29 de abril de ese año, aprovechando la salida de su tío al-Zagal hacia Vélez Málaga, seriamente amenazada por el ejército cristiano, el día 21 de abril43. A partir de esta fecha y hasta el final de las capitulaciones que concluyeron con la rendición de la capital del emirato a los Reyes Católicos, el 25 de noviembre de 1491, Baeza estuvo al servicio del último emir granadino y en su círculo más estrecho, pues tenía trato frecuente, según él mismo escribió, con su familia, incluidas las mujeres, y su personal de servicio más directo ${ }^{44}$. Entre ellos consta la estrecha amistad que le unió con un mercader llamado Abraham Alcaicy, que acompañó a Ibn Kumāša en su misión ante los Reyes Católicos en Sevilla, en enero de 1490, para tratar de hacer cumplir los dos acuerdos alcanzados hasta esa fecha entre el emir y los monarcas cristianos45: el de Córdoba, de julio de 1483, y el de Loja, de mayo de 1486, que a su juicio no comportaban la entrega inmediata de la capital nazarí, tal y como exigían los reyes cristianos alegando esos acuerdos ${ }^{46}$. Este primer acercamiento fue un fracaso y motivó la apertura de hostilidades entre ambos bandos, que trataban de ganar mejor posición sobre el tapete de una futura negociación.

El entendimiento era inevitable, pues les apretaba la escasez de víveres, el exceso de gastos y la llegada del invierno, por lo que se reanudaron los contactos diplomáticos en los que, según Baeza, él mismo intervino para que culminaran con éxito: parece que fue quien propició, tanto la entrada en la Alhambra de los negociadores cristianos que debían dar conclusión al acuerdo, el secretario de los Reyes Católicos Hernando de Zafra y el caudillo Gonzalo Fernández de Córdoba, como logró también el desistimiento por parte de Boabdil de sus mayores recelos ante la capitulación, que se concretaban en la conservación de su dignidad como gobernante y el amparo de la comunidad de fieles, evitando que los conversos fueran impelidos por la fuerza a retornar a la religión cristiana abjurando de la fe islámica47. Ello se acordó durante la noche del 24 de noviembre de 1491, es decir, el día anterior a la firma en el real de la Vega de Granada del acuerdo de rendición por los Reyes Católicos, confirmando con su sello y rúbrica lo asentado por sus embajadores ${ }^{48}$.

Tras la firma de las Capitulaciones, Hernando de Baeza salió de escena igual que entró, de forma brusca y misteriosa, sin esperar a la entrega de la ciudad, dejándonos una escena crepuscular en la que los negociadores de ambos bandos se alejan cabalgando hacia un horizonte de brillante esperanza o de apagada melancolía ${ }^{49}$.

43 Vidal Castro, 2000: 201-202.

${ }_{44}$ E-P, 243, Baeza: X vo-XI ro; RBME, Y/III/6, Baeza: 476 vo.

45 E-P, 243, Baeza: XIII ro; RBME, Y/III/6, Baeza: 478 ro.

${ }^{46}$ Carriazo, 1989: 512-516, 656-658 y 775-781.

${ }_{47}$ E-P, 243, Baeza: XIV ro y vo

${ }^{48}$ La escena narrada por Baeza es confirmada por el relato de Pérez del Pulgar (1527: $\left.16 \mathrm{v}^{\mathrm{o}}-17 \mathrm{r}^{\mathrm{o}}\right)$, persona conocida de Baeza, según él mismo dice (E-P, 243, Baeza: $5 \mathrm{r}^{\mathrm{o}}$; RBME Y/III/6, Baeza: $471 \mathrm{v}^{\mathrm{o}}$ ).

49 Así en los tres manuscritos que han conservado el final de la crónica: el que aporté en mi tesis doctoral (E-P, 243); otro, que he localizado recientemente en la Biblioteca del Palacio Real de Madrid 


\section{Algunas aportaciones no tan biográficas}

Las primeras notas biográficas sobre Hernando de Baeza ajenas a su crónica corresponderían a las ofrecidas por el cronista de los Reyes Católicos Hernando del Pulgar que, además, parece que fue el primero en haber empleado la obra del historiador y trujamán para componer una propia, el Tractado de el origen de los reies de Granada, aunque hay dudas fundadas sobre su autoría ${ }^{5}$. Y aquí podemos destacar dos hechos singulares que van a marcar en lo sucesivo las aportaciones biográficas sobre Baeza: ser incluido en obras historiográficas que emplearon su crónica como fuente fidedigna y de primera mano, y las dudas que se nos presentan de que estas noticias no provengan, en realidad, de los comentarios autobiográficos que Baeza intercaló en sus páginas. En el Tractado, por ejemplo, se dice que fue "intérprete asalariado de los reies moros, i testigo de vista de todos estos subçesos, de los quales tiene vn libro manuscripto que io he visto, de mui entera relaçión de todo" ${ }^{11}$. Es decir, nada que no pueda provenir directamente de los datos contenidos en la Historia de los Reyes moros de Granada. Otra afirmación de este Tractado sobre el contenido de la crónica de Baeza, incluso, pertenece realmente a los Anales de Jerónimo Zurita y no a la crónica de Baeza:

Scribe Fernando de Baeça que, de duçientas mil almas que auía en la çiudad de Granada, aún no eran quinientas de la naçión Africana, sino naturales hespañoles, i godos que se auían mezclado i tomado la lei de los vençedores ${ }^{52}$.

La autoridad del cronista como testigo de los hechos que narró ha provocado en muchos de sus comentaristas este efecto: la fabulación sobre sus circunstancias vitales o sobre los contenidos del texto que legó.

Otro interesante comentario sobre Baeza lo hace el copista anónimo que añadió un íncipit en la portada de la copia de la crónica de Baeza custodiada en la Biblioteca de El Escorial:

Las cosas que pasaron entre los reyes de Granada desde el tienpo de el rey don Juan de Castilla, segundo de este nonbre, hasta que los Cathólicos Reyes ganaron el reyno de Granada, scripto y copilado por Hernando de Baeça, el qual se halló presente a mucha parte de lo que cuenta y lo demás supo de los moros de aquel reyno y de sus corónicas ${ }^{53}$.

(RB, MF/470); y un tercero, descubierto por el profesor Josef Ženka en la Beinecke Rare Book \& Manuscript Library de la Universidad de Yale (Beinecke MS 633).

${ }_{50}$ Seguimos la copia de Biblioteca de la RAE: Ms. 15o, datada en 1518, aunque esta fecha puede corresponder al otro texto que lo acompaña, inequívocamente de Pulgar, Los claros varones de España. Sobre las dudas de atribución: Carriazo, 1989: 394; Salicrú i Lluch, 1998a: 386.

${ }^{51}$ RAE, Ms. 15o, Pulgar: $3 \mathrm{r}^{\mathrm{0}}$.

$5^{2}$ RAE, Ms. 15o, Pulgar, 6 v ${ }^{\circ}$. La cita en: Zurita, 1610: 443.

53 RBME, Y/III/6, Baeza: $465 \mathrm{r}^{\circ}$. 
En este caso apreciamos la idea de un cronista culto, preocupado por documentarse con fuentes fidedignas, lo que tiene visos de realidad si tenemos en cuenta que Baeza pudo contar con fuentes originales árabes para relatar su texto, dadas las muchas concomitancias con textos como la Nubdat al-'așr ${ }^{54}$.

Esta misma impresión continúa en otros autores del XVI que recurrieron a la Historia de los reyes moros de Granada. Es el caso de Francisco de Medina y de Mendoza, autor de la Suma de la vida del reverendísimo cardenal don Pedro González de Mendoza, arzobispo de Toledo. Patriarca de Alejandría55. Medina menciona a Baeza como criado, escritor e intérprete de Boabdil 56 , calificativos que pueden proceder de la lectura de su crónica, sin aportar nada más que las apreciaciones particulares de un lector atento. A la vista de los ejemplares con final de la crónica de Baeza, tampoco podemos situar a este en el momento de la entrega de la capital nazarí, tal y como dice Medina en un texto que no es sino una recreación compuesta con materiales muy diversos, como en su día advirtiera Carriazo ${ }^{57}$.

También podemos aludir a Gabriel Rodríguez de Ardila y Escavias, que usó igualmente de forma declarada la crónica de Baeza en su Origen, descendencia y hazañas de la gran casa de Mendoza $a^{5}$, que sólo conocemos a través de los fragmentos contenidos en otra obra historiográfica, la Historia de la casa de Mondéjar de Gaspar Ibáñez de Segovia59. Según transcribió este último, Rodríguez de Ardila dijo de Baeza que había sido criado de Boabdil y que fue miembro de su consejo ${ }^{6 \circ}$. El parecido de estas palabras literales con las de Medina nos hace sospechar si, en puridad, no seguía más a este último que a la fuente original.

\section{UN NOVEDOSO TESTIMONIO BIOGRÁFICO}

Gracias a la aparición de la copia de la Historia de los reyes moros de Granada que he llamado Escalante-Portilla, por el depósito documental en el que está localizado, he podido obtener un nuevo dato, hasta ahora ignorado, de la vida de Hernando de Baeza: estuvo mucho tiempo cautivo en Granada ${ }^{61}$. La aportación viene dada

${ }^{54}$ El tono general de estas dos crónicas sobre el enfrentamiento civil que asoló Granada durante el gobierno de Abū l-Ḥasan Alī y las atribuciones de responsabilidades, con ligeros matices, son casi absolutamente coincidentes, y hay episodios concretos, como la inundación de la capital nazarí de 1478 (E-P, 243, Baeza: $4 \mathrm{v}^{\mathrm{o}}-5 \mathrm{r}^{\mathrm{o}}$; RBME, Y/III/6, Baeza: $470 \mathrm{v}^{\mathrm{o}}-471 \mathrm{r}^{\mathrm{o}}$ ), en que las coincidencias son indudables (Ženka, 2017). Hay que tener presente que, aunque la redacción de la Nubdat al-'așr fí ajbār mulūk Banī Nașr es del siglo XVII, la obra en la que se basa, Ajbār al-'așr fì inqiḍā' dawlat Banī Naṣr, se redactó en época muy próxima a la Historia de los Reyes moros de Granada, a principios del siglo XVI (López y López y Velázquez Basanta, 2009: 621).

55 Utilizo la copia del siglo XVI: BNE, Mss/9848.

${ }_{56}^{6}$ BNE, Mss/9848: 67 vo-68 $\mathrm{r}^{\circ}$.

57 Carriazo, 1948: 440-442.

${ }_{58}^{8}$ El título completo se puede leer en: (Antonio, 1783: 509).

59 Manejo dos copias diferentes: BNE, Mss. 3315 y BRAH, 9/184.

60 BNE, Mss. 3315: $211 \mathrm{r}^{\mathrm{o}}$ y $212 \mathrm{r}^{\mathrm{o}}$; BRAH, 9/184: $282 \mathrm{v}^{\mathrm{o}}-283 \mathrm{r}^{\mathrm{o}}$ y $284 \mathrm{v}^{\mathrm{o}}$.

${ }^{61}$ E-P, 243, Baeza: XIV vo 
por un amanuense anónimo del códice misceláneo que contiene esta copia y que inserta varios elementos en dos de las tres obras que contiene: en primer lugar, un íncipit en el principio de la crónica de Baeza, en el que indica su nombre y su condición de intérprete, así como el título de la obra, que había sido hasta ahora citada por su íncipit original ${ }^{62}$, por el íncipit añadido en la portada del manuscrito de El Escorial63, o por los títulos ficticios que le dieron sus editores, Müller ${ }^{64}$ y Lafuente y Alcántara ${ }^{65}$; en segundo lugar, añade un colofón, que incluye el título abreviado de la obra, Historia de los reyes moros ${ }^{66}$, así como la mencionada apostilla sobre la vida del autor y su cautiverio; incluye, después, otro íncipit al Memorial de los Reyes Católicos de Lorenzo Galíndez de Carvajal, donde se informa que su autor fue consejero y de la Cámara de los reyes, natural de Plasencia ${ }^{67}$; y, por fin, un título que indica la copia del testamento de la reina Isabel, que se incluye como parte de la obra de Galíndez ${ }^{68}$.

Este dato, añadido de forma marginal por alguien que parecía estar muy informado de los autores que describe, me ha permitido localizar una fuente de archivo que, por primera vez, puede atribuirse con bastante certeza al escritor y trujamán. A falta de un estudio pormenorizado del documento ${ }^{69}$, el Fernando de Baeza que aparece en él tiene muchas trazas de ser el autor de la Historia de los reyes moros de Granada: lugar, fecha y circunstancias coinciden con datos que conocemos de él, o que sospechamos por sus propias palabras, pues se mueve con soltura a través de la frontera entre el reino de Castilla y el emirato de Granada, procede de Baena y permaneció cautivo durante un tiempo en tierras granadinas.

\section{AlgunAs hipótesis No CONClUYentes}

Una de las vías más interesantes para aproximarnos a lo que pudo ser la vida de Baeza tras la conquista de Granada ha sido explorada por varios autores, pero no está exenta de controversia. Se trata de la posibilidad de que Hernando de Baeza permaneciese en contacto con Boabdil y su familia cuando se trasladó allende, es decir, a África, así como que participase en las relaciones entre el reino de Castilla y los territorios islámicos de la frontera africana.

${ }_{62}$ "Hernando de Vaeça, de la suma que hizo estando en Granada de las cosas de aquel reyno" (RBME, Y/III/6, Baeza: $465 \mathrm{~V}^{\mathrm{o}}$ ). Este íncipit está también en los manuscritos completos: (E-P, 243, BAEZA: $1 \mathrm{r}^{\mathrm{o}}$ ).

${ }_{63}$ "Las cosas que pasaron entre los reyes de Granada desde el tienpo de el rey don Juan de Castilla, segundo de este nonbre, hasta que los Cathólicos Reyes ganaron el reyno de Granada" (RBME, Y/III/6, Baeza: $\left.465 \mathrm{r}^{\mathrm{o}}\right)$.

${ }_{4}$ Cosas de Granada (Müller 1863: 57).

65 Últimos sucesos del reino de Granada (Lafuente y Alcántara, 1868: 1).

${ }^{66}$ E-P, 243, Baeza: XIV vo.

67 E-P, 243, Galíndez: XV ro.

68 E-P, 243, Galíndez: XXXII ro.

69 Estudio que ya hemos realizado y que saldrá publicado próximamente. 
En este sentido van encaminados algunos documentos de archivo que, no obstante, omiten el nombre de pila del personaje aludido y se refieren a él por el apellido, y lo vinculan con Martín de Alarcón, quien fuera custodio de Boabdil durante su cautiverio en Porcuna el año 1483 y alcaide de Moclín tras su conquista por los Reyes Católicos en 1486. En primer lugar hay una posible referencia en una carta escrita por la reina Isabel al primer arzobispo de Granada, fray Hernando de Talavera, fechada en Zaragoza, a 4 de diciembre de 1492, y recogida por Francisco Bermúdez de Pedraza:

De la ida del Rey Moro, auemos mucho plazer, y de la ida del Infante su hijo mucho pesar: si yo pudiera lo que vuestra carta dize mas diligencia hiziera por detenerlo, pareceme que alla donde esta lo deuemos siempre cebar, visitandole, con color de visitar a su padre, y embiandole algo. Para esto me embiad a Baeça, el de Martin de Alarcon, que sera bueno para embiarle ${ }^{70}$.

Antonio Suárez de Alarcón ${ }^{71}$ y Clemencín ${ }^{72}$, interpretaron esta cita de distinta manera: el primero pensó en Juan de Baeza, criado de Martín de Alarcón, mientras que Clemencín, por su parte, pensó en nuestro cronista, Hernando de Baeza.

Además de esta, hay otras dos cartas del secretario real Hernando de Zafra quien, tras la conquista de Granada, permaneció en la capital al frente del aparato administrativo de los reyes. Entre sus ocupaciones estuvo la consolidación de las defensas del Reino de Granada, lo que incluía operaciones al otro lado del Estrecho de Gibraltar. En estas cartas, que recogen los preparativos para las incursiones sobre territorio africano, se menciona a un Baeza "el de Moclín"73, que Mariano Gaspar y Remiro y Miguel Ángel Ladero ${ }^{74}$ sugieren sea el intérprete y cronista, mientras que otros autores ${ }^{75}$ se decantan por pensar, de nuevo, en el criado del alcaide de Moclín, dando datos que hacen muy parecidas las biografías de Juan de Baeza con la de nuestro Hernando, sin que se mencionen referencias documentales que lo avalen.

El apoyo de la idea de que el personaje nombrado en estas tres cartas sea nuestro cronista, viene de un pasaje de su crónica en el que se cuenta cómo Baeza soltó

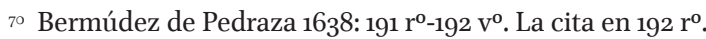

${ }^{71}$ Suárez de Alarcón 1665: 54.

${ }_{72}$ Clemencín 1821: 372-383. La mención a Baeza en 378, y la interpretación en 379.

73 En dos cartas, de 28 de julio de 1493 y de 4 de febrero de 1494 (Pando Fernández de Pinedo y Salvá (eds.), 1867: 67-71 y 75-77, las menciones a Baeza en 70 y 75 ).

74 Gaspar y Remiro 1912: 97; Ladero Quesada, 1967: 21.

75 Villalba González 2008: 32. Descarto una tercera posibilidad: que se esté hablando de Pedro de Baeza, criado de Juan Fernández Pacheco y tenente de Trujillo, de quien se dice tuvo un fuerte desencuentro con Martín de Alarcón que requirió la intervención de la reina Isabel, que logró reconciliarlos y trabar amistad entre ellos (Valladares de Sotomayor, 1791: 30). Su fuerte resistencia al partido de Isabel durante la guerra civil castellana, en apoyo de su señor, el marqués de Villena, no permite pensar que pudiera gozar en algún momento de la confianza de la reina, pese a su indulto en Toledo en 1480 (López Gómez 2015: 216 y 252).

ISSN $1132-0265$

http://dx.doi.org/10.12795/PH.2017.i31.10

Philologia Hispalensis 31/2 (2017) 15-36 
sobre la villa de Moclín a dos cautivos cristianos que fueron trasladados por Martín de Alarcón a presencia de los reyes ${ }^{7}$.

Otra posibilidad es que Baeza hubiera tenido participación en la rota del conde de Cabra ante Moclín, el 3 de septiembre de 148577, y de esa acción, en la que resultó herido el señor de Baena, le hubiera quedado el motejo, pero esta propuesta no puede ir más allá de la mera conjetura.

Tampoco se puede avanzar en otra propuesta en la que he coincidido con Josef Ženka y Teresa Tinsley ${ }^{7}$, en la que se sitúa a Baeza como criado al servicio de Gonzalo Fernández de Córdoba. Es seguro que el cronista conoció al Gran Capitán, de quien hace una sugerente alabanza:

Gonzalo Hernández, alcaide de Yllora, que después por su grand ezelençia y nobleza de su persona, mediante la voluntad de Dios, que le ayudó, cobró renombre de Grand Capitán con mucha raçón, según los hechos hazianosos (sic) (que) hiço ${ }^{79}$.

Pero no vemos posibilidad fehaciente de relacionar al converso Hernando Rodríguez de Baeza, criado del militar durantelas campañas italianas, y su embajador ante la corte pontificia ${ }^{80}$, con nuestro escritor y trujamán. La huidiza personalidad vuelve, en este caso, a dejarnos en suspenso, a falta de nuevas informaciones que permitan asegurar las pesquisas aventuradas en esta vía de investigación.

\section{LO QUE LA FICCIÓN ESCONDE. EL HECHO LITERARIO COMO DISIMULACIÓN DE LA VERDAD}

Las investigaciones iniciadas por Américo Castro ${ }^{81}$ llevaron a definir un marco de vida y una forma de vivirlo, que caracteriza el ser de cada sujeto, dando lugar a una escuela castrista, por definición, que ahonda en los hechos literarios como expresión de esa vividura consciente que se desenvuelve en el inconsciente vital. Es, desde este punto de vista, desde el que podemos rescatar algunos rasgos de la personalidad de Hernando de Baeza perceptibles entre las páginas de su crónica. En este sentido puedo afirmar que hay tres elementos particularmente distintivos de la personalidad del cronista reflejados en las páginas de su crónica:

a) En primer lugar, debemos destacar su particular cultura, reflejada en su texto, compuesta de elementos cultos y populares, es decir, los dos que conforman el

${ }^{76}$ E-P 243, Baeza: 3 vo; RBME, Y/III/6, Baeza: 469 r $^{\circ}$.

77 Carriazo, 1989: 611-613.

$7^{8}$ Ženka, 2011: 67-106; Tinsley, 2016: 543-544.

79 E-P, 243, Baeza:XIII ro ${ }^{\circ}$ RBME Y/III/6, Baeza: 478 ro.

8o Se le nombra en la correspondencia y crónicas del Gran Capitán, por ejemplo: Rodríguez Villa (ed.), 1908: XXXVI de las "Cartas del Gran Capitán" y 389 de la "Crónica manuscrita"; también aparece en la documentación del Archivo Arzobispal de Sevilla: Hazañas y La Rúa, 1918: 356.

${ }^{81}$ Castro, 1954. 
hilván del romancero ${ }^{82}$. En sus páginas se perciben ecos evidentes de este ciclo lírico, caso del famoso romance de Abenámar y el rey don Juan ${ }^{83}$, o el de Garcilaso de la Vega ${ }^{84}$ y, desde luego, el de La prisión del rey Chiquito de Granada ${ }^{85}$. En todos ellos el eco poético se vuelve relato verídico con el aporte de datos concretos de lugares y personajes históricos ${ }^{86}$, y es aquí donde Baeza se convirtió en una fuente impagable para dar historicidad a aquellos romances que le sirvieron para dar un tono literario a su relación histórica; pero, también, para ser usado él mismo como inspiración de nuevos romances. Del primero de los casos destaca la afirmación histórica que Baeza aporta al famoso romance en el que destaca la figura de Abenámar ${ }^{87}$. El romance de Garcilaso también es buen ejemplo del primer caso, pues se atribuyó de forma errónea una notable hazaña bélica a un personaje que no tuvo ocasión de llevarla a efecto, y debe ser atribuido al militar y cronista Fernán Pérez del Pulgar, protagonista de la entrada nocturna en Granada para clavar en la puerta de la mezquita mayor el cartel que es protagonista del hecho narrado por el romance. Es Baeza quien nos descubre la verdad oculta en la ficción romanceada ${ }^{88}$, y los documentos de archivo nos aclaran la historicidad del relato cronístico al dar fe del antagonista musulmán de Pérez del Pulgar en este lance, el Abraham Robledo citado por Baeza ${ }^{89}$, servidor de Boabdili9 ${ }^{\circ}$. En el segundo sentido, es reconocido el uso que el romancero dio al relato de Baeza de la muerte de ciertos caballeros por Abū l-Hasan, entre ellos algún Abencerraje ${ }^{91}$, lo que fue expresado poéticamente culpando a Boabdil del homicidio de su padre, tradición extendida por la ficción novelesca de Ginés Pérez de Hita ${ }^{2}$.

b) En segundo lugar, el reflejo de una particular espiritualidad, que podría definirse como peculiar de la España de finales del cuatrocientos y buena parte de la centuria del quinientos, caracterizada por un cristianismo de corte reformista, que pretendía el regreso a un sentido paulino de la fe, de formas sencillas, en el que

82 En Baeza destaca tanto la referencia a Juan de Mena, poeta cortesano por excelencia del siglo XV español (E-P, 243, Baeza: 6 ro; RBME, Y/III/6, Baeza: 472 vo), como la cita paremiológica: "mataldo (sic) quel muerto no faze mal a nadie" (E-P, 243, Baeza: 3 vo; RBME, Y/III/6, Baeza: $469 \mathrm{r}^{\mathrm{o}}$ ).

83 Galmés de Fuentes (ed.), 1989: 412-413; Menéndez Pidal, 1972: 96.

84 Galmés de Fuentes (ed.), 1989: 426-427.

85 Idem, 422-423.

86 Ladero Quesada, 2002, 75-81.

87 E-P, 243, Baeza: 1 voo RBME, Y/III/6, Baeza: 466 ro. Baeza ha sido citado como fuente de este romance numerosas veces, por ejemplo: Salicrú i Lluch, 1998b: 744 .

88 Brisset Martín, 1988: 243.

89 E-P, 243, Baeza: 5 ro; RBME, Y/III/6, Baeza: 471 vo.

90 AGS RGS, LEG, 148402,13. Ya fue destacado por Carriazo (1948: 439).

${ }^{11}$ En realidad, como ya expuso Menéndez Pelayo, el romance fusionó dos temas planteados por Baeza: el asesinato de Muhammad X y su familia por Sacd, padre de Abū l-Hasan (E-P, 243, Baeza: 2 ro; RBME, Y/III/6, Baeza: 466 vº), y la muerte dada por Abū l-Hasan a varios opositores (E-P, 243, Baeza: 2 $\mathrm{v}^{\mathrm{o}}-3 \mathrm{r}^{\mathrm{o}}$; RBME, Y/III/6, Baeza: $\left.467 \mathrm{~V}^{\mathrm{o}}-468 \mathrm{r}^{\mathrm{o}}\right)$, dando pie a una larga tradición legendaria que llegó hasta el siglo XX (Fosalba, 2002: 316).

$9^{2}$ Blanchard-Demougue, 1913: XLVI-XLVII. 
se valoran los aspectos interiores frente a los formalismos externos. Pero, sobre todo, se define como un cristianismo integrador, que acoge sin ambages a la comunidad conversa por la capacidad del bautismo para recibir de pleno derecho a cualquier persona en la comunidad cristiana, independientemente de sus orígenes. En este sentido, la Granada de fray Hernando de Talavera, su primer arzobispo, fue un marco de irradiación de tolerancia hacia el mundo converso ${ }^{93}$. En el primer sentido aludido, el pasaje de la batalla de Lucena y las referencias al conde de Cabra son más que significativas, pues no solo se aprecia una singular estima de la laicidad entendida con valor propio para la vivencia de la fe, cuando define al conde de Cabra como verdadero santo por su vida virtuosa, sino que, además, pone en valor la preeminencia de la voluntad sobre el acto en la escena de la comunión espiritual llevada a cabo en el campo cristiano y nos descubre, por fin, el origen de este peculiar modo de sentir religioso: los ambientes jerónimos en los que confiesa moverse el autor $^{94}$, tan proclives a la idea de retorno a los orígenes de un cristianismo sencillo y profundamente espiritual, y abiertamente favorables a la realidad conversa ${ }^{95}$. En el segundo de los sentidos aludidos tenemos, a lo largo de la crónica, numerosos ejemplos, que han dado lugar a que sea considerada como verdadero alegato de la condición conversa hasta el punto de haber sido considerada la crónica elche de la Granada nazarí96 ${ }^{6}$. En este sentido tenemos numerosas alusiones a la inocencia y buen fondo de los conversos elches, y a su integridad moral, que llega al punto de reconocerlos informantes de todo crédito para obtener noticias fidedignas de los sucesos de la Granada nazarí97. Pero, de todas las alusiones, destaca la referida al propio Boabdil, de quien Baeza dice:"y realmente creo que sy alcançara a ser cristiano, que fuera vno de los mejores que jamás fueron"98. No cabe mayor expresión sobre la capacidad redentora del bautismo y el aprecio de los rasgos personales sobre las consideraciones externas a la persona, sean de raza, cultura o religión. El hallazgo del final de la crónica permite reforzar esta idea con un nuevo fragmento, en el que singulariza la condición de los conversos y muestra la peculiaridad jurídica con la que permanecían en el territorio ocupado a raíz de las capitulaciones99. Baeza solo hace referencia explícita a dos de los puntos de las negociaciones entre Boabdil y los Reyes Católicos, condiciones sine qua non para el emir nazarí: el modo de rendición de la capital, en el que se preservaba la dignidad del último emir, librándole de la fórmula tradicional de homenaje, que se transformaba en un saludo habitual entre los musulmanes ${ }^{100}$; y la exigencia de respetar a la comunidad conversa de Granada

${ }_{93}$ Esta espiritualidad heterodoxa característica de la religiosidad hispana puede verse con detalle en: Pastore, 2010.

94 E-P, 243, Baeza: 6 vo; RBME, Y/III/6, Baeza: 473 r $^{\circ}$ y vo $^{\circ}$.

95 Pastore, 2010: 50-69.

${ }_{96}^{6}$ López de Coca Castañer, 2005: 34.

${ }_{97}$ E-P, 243, Baeza: 3 vo $^{\text {- }} 4$ r $^{\text {o }}$ y XI ro y vo ; RBME, Y/III/6, Baeza: 469 r $^{\circ}$ y vo y 477 ro $^{\circ}$.

${ }_{98}^{8}$ E-P, 243, Baeza: XI ro ${ }^{\circ}$ RBME, Y/III/6, Baeza: 477 ro .

99 E-P, 243, Baeza: XIV vo

${ }_{100}$ Guevara, 1603: 59. 
tras la conquista. Sobre ambos particulares Baeza comenta su intervención directa, siendo así, según sus palabras, que pudo desbloquear la negociación; aunque hoy se duda de la verdadera intención de las Capitulaciones sobre la realidad de los elches ${ }^{101}$.

c) Aún queda otro aspecto por destacar, menos evidente, pero que se entrevé en las páginas de la crónica. Me refiero a su más que probable servicio como agente doble. El espionaje era característico en la frontera de Granada, como lo es en cualquier ámbito fronterizo ${ }^{102}$, y es conocida, a través de Pérez del Pulgar, la red de espías que había creado Gonzalo Fernández de Córdoba, muy activa en la capital del emirato, y la especial participación que tuvieron en los tratos que condujeron al éxito de las capitulaciones ${ }^{103}$. En este contexto pueden entenderse algunos pasajes autobiográficos de la crónica dentro de la actividad encubierta de un agente al servicio de dos señores, los reyes cristianos, por un lado, y el último de los gobernantes nazaríes, por otro. En concreto, las palabras de Baeza sobre el rescate que propició de dos elches oriundos de Villacarrillo y Cieza, conduciéndolos ante Martín de Alarcón ${ }^{104}$ y, sobre todo, un episodio hasta ahora desconocido, que se encuentra en las copias con final, y que parece complementarse a la perfección con la narración de estos mismos hechos por Pérez del Pulgar ${ }^{105}$. Leemos en Baeza:

A pocos días començaron los tratos, y Gonçalo Hernández de Córdoba, que después fue llamado Grand Capitán, juntamente con Fernando de Çafra, secretamente vna noche entraron por el Alhambra traídos por el rei moro con vn cauallero moro que ya abía salido dos, y avn tres vezes, secretamente al real, y porque este caballero no fiçiese algún engaño al rei moro, como ya otra vez lo abía cometido a façer, yo lo conçejé al rey (Boabdil).

Esta (sic) concuerdo e mandamiento que me fue enviado secretamente con vn cautibo que yo abía soltado de ençima de Marbella, de sus altezas, en que me mandaban diesen horden cómo aquellos caualleros pudiesen entrar seguros, porque más çiertas e prestamente darían conclusión los negocios, asy por la grande costa que se aría en el real, como porque el ynbierno se venía y fatigaba la jente ${ }^{106}$.

Este tono, compuesto por múltiples y ricas facetas características de una España todavía multicultural, vino muy bien a otro género, el de la narrativa histórica, que se sirvió de la Historia de los reyes moros de Granada para recrear con tintes verídicos su creación legendaria. El caso más llamativo, sin duda alguna, es el de Ginés Pérez de Hita, que utiliza un acopio extraordinario de fuentes, desde la historia a los

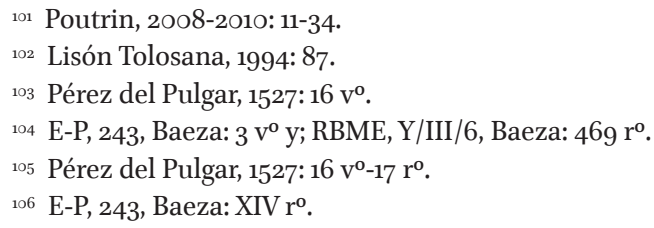


romances, y seguramente la crónica de Baeza, pero ofreció un relato en el que, a su sabor, pintó a los personajes en función de sus necesidades literarias, sin importar que se alejasen de la verdad de los hechos históricos, lo que hace que dibuje una personalidad de Boabdil completamente opuesta a la imagen presentada por Baeza $^{107}$.

\section{CONCLUSIÓN. LA UBICUA PERSONALIDAD FRONTERIZA}

El umbral de la frontera geográfica, siempre difusa y casi imperceptible en sus límites físicos, se ha definido por su dialéctica interno/externo, inclusión/ exclusión ${ }^{108}$, y ha marcado con su peculiaridad ambigua a las gentes que habitan entre límites. Esta ambigüedad se ha reflejado eficazmente en la literatura de frontera, con elementos que pasan de la rivalidad a la empatía, de la filia a la fobia, del enfrentamiento a la amistad, pasando a uno y otro lado de la frontera ${ }^{109}$. Cuando esta desapareció, la marca quedó inserta en el espíritu de las gentes que se formaron en los espacios fronterizos y singularizó su carácter orientándolo hacia un especial modo de sentir la diferencia.

Podemos establecer un paralelismo biográfico entre Hernando de Baeza y otro personaje de peculiar biografía, Hernando del Pulgar, de quien ya he dicho pudo ser el primer escritor que empleó la Historia de los reyes moros de Granada como fuente histórica ${ }^{110}$. Tras la redacción de esta obra, Hernando del Pulgar, al igual que su homónimo de Baeza, desapareció de la escena histórica y se pierde en la neblina del tiempo. Este hecho no parece casual y puede compartir motivo con las sospechas lanzadas por algunos historiadores sobre la curiosa falta de noticias con la que se cierra la biografía del famoso cronista de los Reyes Católicos ${ }^{111}$, de manera que podríamos atribuir la desaparición del cronista de los nazaríes a una causa semejante: la necesidad de ocultar a los ojos inquisidores sus orígenes confesos tras la implantación del Santo Oficio en Castilla el año 1480 y la creciente presión sobre el grupo converso en los años posteriores al Decreto de Expulsión de los judíos del reino en 1492. Estas amenazas se exacerbaron de forma creciente hasta la represión del inquisidor Lucero, que llevó al extremo las consecuencias de la nueva política regia contra los cristianos nuevos, viéndose afectados por esta nueva política figuras tan señeras como el arzobispo Talavera ${ }^{112}$.

La caída de Granada determinó, indudablemente, el final de una época singularizada por las luces y sombras de la convivencia entre las tres religiones del

107 Blanchard-Demougue, 1913 : L-LI.

${ }^{108}$ Lisón Tolosana, 1994: 82.

109 Idem.

110 Queda pendiente la cuestión de si el anónimo autor del apócrifo Tractado pudo haberse servido, en efecto, de alguna obra o borrador elaborado por Pulgar que quedó incompleto por la repentina desaparición del cronista oficial.

i1 Zinato, 2004: 25 o.

112 Pastore, 2010: 114-115. 
Libro, y la obra de Hernando de Baeza, "peregrino autor cristiano" en definición de Gaspar de Remiro ${ }^{113}$, nos ha dejado un testimonio de primera mano de los brillos y oscuridades que marcaron ese convivir.

\section{REFERENCIAS BIBLIOGRÁFICAS}

Alarcón, Pedro Antonio de (1874): La Alpujarra. Sesenta leguas á caballo, precedidas de seis en diligencia. Madrid: Imprenta y Librería de Miguel Guijarro.

ARIÉ, Rachel (1981): “Le royaume nașride de Grenade: réalité et légende”, Awraq 4, 149-165 .

ARIÉ, Rachel (2001): "La visión de la Alhambra en ciertas obras románticas", en: Alcantud, J.A./Malpica Cuello, A. (eds.): Pensar la Alhambra. Rubí, Barcelona: Anthropos, 201-223.

Blanchard-Demougue, Paula (ed.) (1913): "Introducción" en: Pérez de Hita, Ginés (id.): Guerras civiles de Granada. Vol. 1. Madrid: Imprenta de E. Bailly-Baillière, VIII-CXVIII.

CARrasco Urgoiti, María Soledad (1956): El moro de Granada en la literatura: del siglo XV al XIX. Madrid: Revista de Occidente.

BRISSET MARTíN, Demetrio E. (1988):Representaciones rituales hispánicas de conquista. Tesis doctoral. Madrid: Universidad Complutense de Madrid.

CARriazo, Juan de Mata (1948): "Una continuación inédita de la Relación de Hernando de Baeza", Al-Andalus. Revista de la Escuelas de Estudios Árabes de Madrid y Granada 13, 2, 431-442.

CARriazo, Juan de Mata (1989): “Historia de la Guerra de Granada”, en: Suárez Fernández, Luis/Mata Carriazo Arroquia, Juan de (eds.): La España de los Reyes Católicos (1474-1516). Vol. 1. Madrid: Espasa-Calpe.

CAStro, Américo (1954): La realidad histórica de España. México: Porrúa.

CEJADOR Y FRACUA, Julio (1915): Historia de la lengua y literatura castellana (desde los orígenes hasta Carlos V). Madrid: Tipografía de la Revista de Archivos, Bibliotecas y Museos.

Clemencín, Diego (1821): "Ilustraciones sobre varios asuntos del reinado de doña Isabel la Católica que pueden servir de pruebas á su elogio, presentadas á la Academia de la Historia" en: Montalbán, Juan Manuel/Guerra, Francisco/Sancha, Antonio de (eds.): Memorias de la Real Academia de la Historia. Vol. 6. Madrid: Imprenta de I. Sancha, 55-577.

Coromines, Joan/Pascual, José A. (2001): Diccionario crítico etimológico castellano e hispánico. Madrid: Gredos.

Deferrari, Harry Austin (1927): The sentimental Moor in Spanish literature before 1600. Philadelphia: University of Pennsylvania.

DURÁN Y LERCHUNDI, Joaquín (1893): La toma de Granada y caballeros que concurrieron á ella. Vol. 1. Madrid: Imprenta y Litografía de los Huérfanos.

EGUILAZ Y YANGUAS, Leopoldo de (1886): Glosario etimológico de las palabras españolas... de origen oriental... Granada: Lealtad.

EsPinar Moreno, Manuel (1995): “La voz de los mudéjares de la aljama de Guadix", Sharq al-Andalus 12, 85-128.

Fosalba, Eugenia (2017): "Estudio y anexos" en: Fosalba, Eugenia (ed.): El Abencerraje. Madrid: Real Academia Española, 83-296.

${ }^{113}$ Gaspar y Remiro, 1911: 27.

ISSN $1132-0265$

http://dx.doi.org/10.12795/PH.2017.i31.10

Philologia Hispalensis 31/2 (2017) 15-36 
Fosalba, Eugenia (2002): “Sobre la verdad de los Abencerrajes", Boletín de la Real Academia de Buenas Letras de Barcelona 48, 313-334.

Funes PÉREZ, José Antonio (2016): Evolución de las actividades deportivas de las provincias de Granada, Córdoba y Jaén entre los siglos Xy XVII. Tesis doctoral. Granada: Universidad de Granada.

GALMÉS DE Fuentes, Álvaro (ed.) (1989): El romancero hispánico. León: Everest.

García Esteban, Ana Pilar (2015): Edición y estudio de dos romances fronterizos: jAy de mí Alhama! y El alcaide de Alhama. Tesina de Fin de Máster. Madrid: Universidad Complutense de Madrid.

GASPAR y REMIRo, Mariano (1912): "Partida de Boabdil allende con su familia y principales servidores", Revista del Centro de Estudios Históricos de Granada y su Reino 2, 68-74.

GASPAR y Remiro, Mariano (1911): "Documentos árabes de la corte nazarí de Granada", Madrid: Tipografía de la "Revista de Archivos, Bibliotecas y Museos".

GILBERT, Claire Morgan (2014): The politics of Language in the Western Mediterranean c. 1492-c. 1669: Multilingual Institutions and the Status of Arabic in Early Modern Spain. Tesis doctoral. Los Angeles: University of California.

Gozalbes Gravioto, Enrique (1999): "El epílogo de la Granada nazarí en la obra de Hernando de Baeza" en: Temimi, Abdeljelil (ed.):Mélanges Ma. Soledad Carrasco Urgoiti. Vol. 1. Zaghouan: Fondation Temimi pour la Recherche Scientifique et l'Information, 63-71.

GonZÁlez de AMEZÚA y MAYO, Agustín (1915): La batalla de Lucena y el verdadero retrato de Boabdil. Estudio histórico-artístico. Madrid: Imprenta Clásica Española.

Guirao López, José (1966): "Boabdil, último rey moro de Granada, estuvo refugiado en Lorca (1485)", Murgetana 26, 97-106.

HAZAÑAS Y LA RÚA, Joaquín (1918): Vázquez de Leca, 1573-1649. Sevilla: Imprenta y Librería de Sobrinos de Izquierdo.

LADERo QUESADA, Miguel Ángel (2002): Las guerras de Granada en el siglo XV. Barcelona: Ariel.

LAdero QuesadA, Miguel Ángel (1967): "La defensa de Granada a raíz de la conquista. Comienzos de un problema”, Miscelánea de estudios árabes y hebraicos. Sección ÁrabeIslam 16, 7-46.

LAfuente AlcÁntara, Miguel (1846): Historia de Granada. Comprendiendo las de sus cuatro provincias, Almería, Jaén, Granada y Málaga, desde remotos tiempos hasta nuestros días. Vol. 4. Granada: Imprenta y Librería de Sanz.

LAFUENTE Y AlCÁNTARA, Emilio (1868): Relaciones de algunos sucesos de los últimos tiempos del Reino de Granada. Madrid: Sociedad de Bibliófilos Españoles.

Lisón Tolosana, Carmelo (1994): "Antropología de la frontera", Revista de antropología social $3,75-103$.

López DE Coca Castañer, José Enrique (2005): "La conquista de Granada: el testimonio de los vencidos", Norba. Revista de Historia 18, 33-50.

López Gómez, Óscar (2015): “Traición y supervivencia política en tiempos de los Reyes Católicos: Juan de Luján, regidor de Madrid, alcaide de Escalona, gobernador de Elche" en: Galende Díaz, Juan Carlos/Cabezas Fontanilla, Susana (dirs.); Ávila Seoane, Nicolás (coord.): Madrid: su pasado documental. Madrid: Universidad Complutense, 203-227. 
LóPez y LóPez, Ángel C./VelázQuez BASANTA, Fernando Nicolás (2009): “Nubd̄at al-'așr fī ajbār mulūk Banī Nașr”, en: Lirola Delgado, Jorge/Puerta Vílchez, José Miguel (eds.): Biblioteca de al-Andalus: De Ibn al-Ŷabbāb a Nubdat al-'aṣr. Vol. 6. Almería: Fundación Ibn Tufayl de Estudios Árabes, 621-622.

MACKAY, Angus (1988): "Los romances fronterizos como fuente histórica”, en: Segura Gariño, Cristina (coord.): Relaciones exteriores del reino de Granada: IV del Coloquio de Historia Medieval Andaluza. Almería: Instituto de Estudios Almerienses, 273-285.

Mata IndurÁIn, Carlos (1995): "Retrospectiva sobre la evolución de la novela histórica", en: Spang, Kurt/Arellano, Ignacio/Mata, Carlos (eds.): La novela histórica. Teoría y comentarios. Barañáin: Ediciones Universidad de Navarra, 13-63.

Menéndez Pelayo, Marcelino (1949): Estudios sobre el teatro de Lope de Vega. Crónicas y leyendas dramáticas de España. Santander: Aldus.

MenÉndez Pelayo, Marcelino (1944): Antología de poetas líricos castellanos. Vol. 7. Madrid: Consejo Superior de Investigaciones Científicas.

MenÉndez Pelayo, Marcelino (1943): Orígenes de la novela. Vol. 2. Madrid: Consejo Superior de Investigaciones Científicas.

MEnÉndez PIDAL, Ramón (1973): Estudios sobre el romancero. Madrid: Espasa-Calpe.

Menéndez Pidal, Ramón (1972): Los romances de América y otros estudios. Madrid: Espasa-Calpe.

MENÉndez PidAL, Ramón (1916): "Poesía popular y romancero", Revista de Filología Española $3,3,233-289$.

Morales Oliver, Luis (1972): La novela morisca de tema granadino. Madrid: Universidad Complutense de Madrid, Fundación Valdecilla.

MüLleR, Marc Joseph (1863): Die Letzen Zeiten von Granada. München: Christian Kaiser.

O'Callaghan, Joseph (2014): The Last Crusade in the West. Castile and the Conquest of Granada. Philadelphia: University of Pennsylvania.

PASTORE, Stefania (2010): Una herejía española. Conversos, alumbrados e Inquisición (14491559). Madrid: Marcial Pons.

Porras Arboledas, Pedro Andrés (2003): “Los reinos occidentales”, en: Porras Arboledas, Pedro Andrés/Ramírez Vaquero, Eloísa/Sabaté i Curull, Flocel: La época medieval: administración y gobierno. Tres Cantos: Istmo, 13-170.

Poutrin, Isabelle (2008-2010): "Los derechos de los vencidos: Las capitulaciones de Granada (1491)", Sharq al-Andalus 19, 11-34.

Quesada CAÑAVERAl y PiÉdrola, Julio (1925): Boabdil (reseña para el turista). Granada y la Alhambra hasta el siglo XVI. Granada: Artes Gráficas Granadinas.

Rodríguez Villa, Antonio (ed.) (1908): Crónicas del Gran Capitán. Madrid: Librería Editorial de Bailly Bailliére e Hijos.

Ruiz Povedano, José María (2009): Colección de documentos para la historia de Alcaudete (1240-1516). Alcaudete: Ayuntamiento de Alcaudete.

SAliCRú I Lluch, Roser (1998a): El sultanat de Granada i la Corona d'Aragó, 1410-1458. Barcelona: Consell Superior d'Investigacions Científiques, Institució Milà i Fontanals.

SALICRÚ I LLUCH, Roser (1998b): "Caballeros granadinos emigrantes y fugitivos en la Corona de Aragón durante el reinado de Alfonso el Magnánimo”, en: Toro Ceballos, Francisco/ 
Rodríguez Molina, José (coords.): Actividad y vida en la frontera. II Estudios de Frontera. Jaén: Diputación Provincial, 727-748.

SÁnchez Alonso, Benito (1947): Historia de la historiografía española. Vol. 1. Madrid: Consejo Superior de Investigaciones Científicas.

Simonet, Francisco Javier (1897-1903): Historia de los mozárabes de España. Deducida de los mejores y más auténticos testimonios de los escritores cristianos y árabes. Vol. 1. Madrid: Establecimiento Tipográfico de la Viuda e Hijos de M. Tello.

STEIGER, Arnald (1932): Contribución a la fonética del hispano-árabe y de los arabismos en el ibero-románico y el siciliano. Madrid: Centro de Estudios Históricos.

SzPIECH, Ryan (2017): "Conversion as a historiographical problem. The case of Zoraya/Isabel de Solís” en: Fox, Yaniv/Yisraeli, Yosi (eds.): Contesting Inter-Religious Conversion in the Medieval World. London, New York: Routledge, 24-38.

Tinoco DíAZ, José Fernando (2017): La cruzada en las fuentes cronísticas castellanas de la Guerra de Granada. Tesis doctoral. Universidad de Extremadura.

Tinoco DíAz, José Fernando (2015): Repertorio bibliográfico de fuentes cronísticas castellanas para el estudio de la Guerra de Granada (1482-1492). Trabajo de Fin de Máster. Universidad de Extremadura.

Tinsley, Teresa (2016): "Hernando de Baeza and the 'Failure' of Multiculturalism after 1492" En: Toro Ceballos, Francisco/Rodríguez Molina, José (coords.): Estudios de frontera. 10. Fronteras multiculturales. Homenaje a Pedro Martínez Montávez. Congreso celebrado en Alcalá la Real, 5 y 6 de junio de 2015. Jaén: Diputación Provincial de Jaén, 541-550.

TorRe, Antonio de la (1944): "Los Reyes Católicos y Granada: relaciones y convenios con Boabdil de 1483 a 1489”, Hispania: revista española de historia 16, 339-382.

ToRRES BALBÁs, Leopoldo (1948): "Dār al-'Arūsa y las ruinas de palacios y albercas granadinos situados por encima del Generalife", Al-Andalus 13, 185-203.

ToRREs FonTEs, Juan (1972-1973): "La historicidad del romance Abenámar, Abenámar", Anuario de estudios medievales 8, 225-256.

VeLÁzQuez BASANTA, Fernando Nicolás (2002): "La relación histórica sobre las postrimerías del Reino de Granada, según Aḥmad al-Maqqarī (s. XVII)”, en: Moral, Celia del (coord.): En el epílogo del Islam andalusí: La Granada del siglo XV. Granada: Universidad de Granada, 481-554.

VidAl CAStro, Francisco (200o): "Historia política”, en: Viguera Molins, María Jesús (coord.): El reino nazarí de Granada (1232-1492). Política, instituciones, espacio y economía. Madrid: Espasa-Calpe, 49-248.

Viguera Molins, María Jesús (200o): “El ejército”, en: Viguera Molins, María Jesús (coord.): El reino nazarí de Granada (1232-1492). Política, instituciones, espacio y economía. Madrid: Espasa-Calpe, 429-475.

VILAR SÁNCHEZ, Juan Antonio (2004): 1492-1502. Una década fraudulenta. Historia del reino cristiano de Granada desde su fundación, hasta la muerte de la reina Isabel la Católica. Granada: Alhulia.

Villalba González, Miguel (2008): Los alguaciles de Melilla. Melilla: Ciudad Autónoma de Melilla.

ŽENKA, Josef (ed.) (2011): "Hernando de Baeza, Zpráva o některých událostech, jež se odehrály v Granadě”, en: Ženka, Josef (ed.): Pád Granady a zánik al-Andalusu. Prahe: Argo, 2011, 67-106. 
ŽENKA, JoSEF (2017): "Las notas manuscritas como fuente sobre la Granada del siglo XV: La gran inundación del año 1478 en un manuscrito escurialense”, Miscelánea de Estudios Árabes y Hebraicos. Sección Árabe-Islam 66, 265-278.

ZinATo, Andrea (2004): "Un memoriale della Spagna dei Re Cattolici: l'epistolario di Fernando del Pulgar", en: Cusato, Domenico Antonio et al. (coords.): Atti del XXI Convegno [Associazione Ispanisti Italiani]: Salamanca, 12-14 settembre 2002. Vol. 1. Messina: Andrea Lippolis, 247-258.

\section{Fuentes Documentales}

ANTONIO, Nicolás (1783): Bibliotheca hispana nova sive hispanorum scriptorum qui ab anno MD ad MDCLXXIV floruere notitia. Vol. 1. Madrid: Joaquín de Ibarra.

Archivo General de Simancas, PTR, LEG, 11, DOC.8. "Seguros del Rey Fernando el Católico en que tomó a los partidarios de Boabdil y de Castilla". 1483/07/05.

Archivo General de Simancas, RGS, LEG, 148402,13. "Exención de pedidos y monedas a Mahomed Robledo y su familia". 1484/02/12, Tarazona.

Archivo General de Simancas, RGS, LEG, 148311, 2. "Título de Don a Diego Fernández de Córdoba por la captura de Boabdil". 1483/11/20, Vitoria.

Archivo General de Simancas, RGS, LEG, 148311, 3. "Alcaidía de los donceles a Diego Fernández de Córdoba por capturar a Boabdil". 1483/11/20, Vitoria.

Archivo General de Simancas, RGS, LEG, 148311, 4. "Merced de los pedidos y monedas de Baena a Diego Fernández de Córdoba". 1483/11/20, Vitoria.

Biblioteca Nacional de España, Ms./9848.

Biblioteca Nacional de España, Ms. 3315.

Biblioteca de la Real Academia de la Historia, 9/184.

Biblioteca de la Real Academia de la Historia, Ms. 15 o.

Beinecke Rare Book \& Manuscript Library, Ms 633.

Bermúdez de Pedraza, Francisco (1638): Historia eclesiástica, principios y progresos de la ciudad y religión católica de Granada, corona de su poderoso reyno, y excelencias de su corona. Granada: Imprenta Real.

Documentos relativos á los reyes Católicos sobre sucesos y negocios en Andalucía después de la conquista de Granada, en: Pando Fernández de Pinedo, Manuel/Salvá, Miguel (1867): Colección de documentos inéditos para la historia de España. Vol. 51. Madrid: Imprenta de la viuda de Calero, 46-127.

Escalante-Portilla, Ms. 243.

Fragmento de la época sobre noticias de los Reyes Nazaritas o Capitulación de Granada y Emigración de los andaluces a Marruecos. Texto árabe con prólogo, notas, comentarios e índices a cargo de Alfredo Bustani; la versión española ha sido hecha por Carlos Quirós. Larache: Artes Gráficas Boscá, 1940.

Guevara, Antonio de (1603): II parte de las Epístolas familiares. Amberes: En casa de Martín Nucio a Las dos cigüeñas.

Marineo Sículo, Lucio (1539): De las cosas memorables de España. Alcalá de Henares: Juan de Brocar.

Palencia, Alonso de [1492?]: Guerra de Granada. Vol. 5. Traducción de Paz y Meliá. Madrid: Tipografía de la "Revista de Archivos", 1909. 
PÉREZ Del Pulgar, Hernán (1527). Breve parte de las hazañas del excelente nombrado Gran Capitán. Sevilla: Jacobo Cromberger.

Real Biblioteca, MF/470.

Real Biblioteca del Monasterio del Escorial, Y/III/6.

SuÁrez de Alarcón, Antonio (ed.) (1665): Comentarios de los hechos del señor Alarcón, marqvés de la Valle Siciliana, y de Renda, y de las guerras en que se halló por espacio de cinquenta y ocho años. Madrid: Diego Díaz de la Carrera.

Valladares de Sotomayor, Antonio (1791): "Valor de Pedro de Baeza en defensa del Alcazar de Truxillo" en: Semanario erudito que comprehende varias obras inéditas, críticas, morales, instructivas, políticas, históricas, satíricas, y jocosas de nuestros mejores autores. Vol. 35. Madrid: Antonio Espinosa, 28-30.

Zurita, Jerónimo (1610): Anales de la Corona de Aragón. Vol. 1. Zaragoza: En el Colegio de S. Vicente Ferrer, por Lorenço de Robles. 